\title{
Daily variability of air pollution in locations of different population density
}

\author{
Robert Cichowicz ${ }^{1, *}$, and Artur Stelęgowski ${ }^{1}$ \\ ${ }^{1}$ Lodz University of Technology, Faculty of Civil Engineering, Architecture and Environmental \\ Engineering, al. Politechniki 6, 90-924 Lodz, Poland
}

\begin{abstract}
The air quality levels vary during a day, especially in inhabited areas. Therefore, it seems reasonable to observe and analyze the occurrence of daily maximum and minimum level of air pollution. In this article, data obtained from automatic air quality monitoring stations located in 5 large, 5 small and medium cities and 5 villages in Poland was analyzed in 2012-2016. Those locations vary, inter alia, depending on number of inhabitants and population density, and for this reason also due to the presence of air contaminants. As an indicator of daily variability air pollution it was determined the ratio of maximum to minimum concentrations of selected air pollutants $\left(\mathrm{NO}_{2}\right.$ and $\mathrm{NO}_{\mathrm{x}}$, and $\mathrm{O}_{3}, \mathrm{SO}_{2}, \mathrm{CO}$, $\mathrm{PM}_{10}$ and $\mathrm{PM}_{2.5}$, and benzene) in urban and agricultural areas. In winter, the daily changes were bigger in cities than in villages. While in summer, the level of daily variability was similar, irrespective of size of the settlement unit. The biggest daily changes concerned nitrogen oxides, the lowest - sulfur dioxide and dusts.
\end{abstract}

\section{Introduction}

Air pollution affects, in different ways, the state of the environment. This impacts the state of fauna and flora, and pose a threat to human health in exposed areas [1-3]. Nitrogen oxides, sulfur oxides, tropospheric ozone and dusts are the so-called "classic air pollutants". Primarily, they have a harmful effect on the human respiratory system [4-6]. Other air pollutants can be toxic, such as carbon monoxide, which achieves low concentrations in atmospheric air, or carcinogenic, such as benzene [7-10]. Today, steps are being taken to significantly reduce the air pollutant emissions [11], and also to better understand the processes of their formation and dispersion in the air [12-16]. Anthropogenic sources of air pollution in Europe are mainly: intensity of road transport, activity of the power sector, and other types of burning fossil fuels [17].

Due to variable activity of emission sources, and changes in meteorological conditions, the concentration of air pollutants varies during a day. However, the nature of changes depends on the density of emission sources, and hence indirectly on the density of population in the considered areas. In large cities there are usually higher concentrations of air pollutants than in less urbanized areas, and unfavorable air quality conditions deteriorate

\footnotetext{
${ }^{*}$ Corresponding author: robert.cichowicz@p.lodz.pl
} 
health of its citizens [18]. However, the level of air pollution vary from hour to hour. Therefore, it was decided to carry out an analysis of daily variability in concentrations of air pollutants, in fifteen selected areas of different settlement size and density, in Poland, Europe.

\section{Materials and methods}

The analysis was based on the measurements of average hourly concentrations from automatic air monitoring stations. The monitoring data came from the years 2012-2016, and the monitoring stations belonged to the Provincial Inspectorates of Environmental Protection in Poland. For the purpose of the analysis, fifteen different locations were selected in central Poland (Table 1). From those were distinguished cities, towns and villages. Settlements with over 50,000 inhabitants and density of at least 1,500 inhabitants $/ \mathrm{km}^{2}$ were treated as cities [19]. Towns (small and medium sized towns) were defined as settlements with population of 25,000-100,000 inhabitants and up to 1500 inhabitants $/ \mathrm{km}^{2}$, or 5,000-25,000 inhabitants and over 300 inhabitants $/ \mathrm{km}^{2}$ [20]. Villages were defined as settlements that did not meet population criteria for very small towns. This means that villages had up to 5,000 inhabitants, did not have city rights, and had up to 300 inhabitants $/ \mathrm{km}^{2}$.

Table 1. Selected locations in Poland.

\begin{tabular}{|c|c|c|c|}
\hline Settlement type & Name & Population, (inh) & Density, (inh/ $\mathbf{k m}^{\mathbf{2}}$ ) \\
\hline \multirow{4}{*}{$*$} & Wrocław & 639,000 & 2181 \\
\cline { 2 - 4 } & Poznań & 539,000 & 2057 \\
\cline { 2 - 4 } & Lódź & 690,00 & 2354 \\
\cline { 2 - 4 } & Warsaw & $1,765,000$ & 3412 \\
\cline { 2 - 4 } & Lublin & 340,000 & 2310 \\
\hline \multirow{4}{*}{} & Kłodzko & 27,000 & 1098 \\
\cline { 2 - 4 } & Konin & 75,000 & 919 \\
\cline { 2 - 4 } & Piotrków Tryb. & 74,000 & 1114 \\
\cline { 2 - 4 } & Piastów & 23,000 & 3977 \\
\cline { 2 - 4 } & Biała Podlaska & 57,000 & 1159 \\
\hline \multirow{4}{*}{} & Osieczów & 345 & $<300$ \\
\cline { 2 - 4 } & Piaski & 124 & $<300$ \\
\cline { 2 - 4 } & Gajew & 114 & $<300$ \\
\cline { 2 - 4 } & Belsk Duży & 790 & $<300$ \\
\cline { 2 - 4 } & Obrocz & 525 & \\
\hline
\end{tabular}

Air quality monitoring stations were located in areas of different characteristics, inter alia, with different assumed density of pollution emission sources and population (Table 2). The air pollution (considering $\mathrm{PM}$ and $\mathrm{NO}_{\mathrm{x}}$ ) is usually the highest in the high-traffic sites, lower in the highly-populated areas, and the lowest in the rural areas [21-23]. This is mainly due to conjestion of non-industrial and traffic emissions. In Poland, which has a coal-based economy, these pollution sources contribute to $30 \%$ of $\mathrm{SO}_{2}, 42 \%$ of $\mathrm{NO}_{\mathrm{x}}, 55 \%$ of $\mathrm{PM}_{2.5}$, and $81 \%$ of $\mathrm{CO}$ emissions [24]. Power industry contributes to $45 \%$ of $\mathrm{SO}_{2}, 25 \%$ of $\mathrm{NO}_{\mathrm{x}}, 9 \%$ of $\mathrm{PM}_{2.5}$, and $2 \%$ of $\mathrm{CO}$ emissions. However, the pollution from power generation usually wide-spreads and dillutes across large area.

From analyzed locations in cities, there were distuinguished areas of: urban traffic, city background, and suburban background. In towns - town background areas, and in villages - rural background areas. However, the urban traffic and suburban background areas were defined only in the following large cities: Wrocław, Łódź, Warsaw. The UT areas were 
affected mostly by road traffic emissions. In CB, SB and TB areas occurred mostly traffic and non-industrial emission sources. And in RB areas the air pollution came mostly non-industrial combustion and agriculture. Also, in each location there was some background pollution, originated, inter alia, from power industry.

Table 2. Assumed population density in the areas of air quality monitoring stations.

\begin{tabular}{|c|c|c|}
\hline Station type & $\begin{array}{c}\text { Assumed density of air pollution } \\
\text { emissions }\end{array}$ & $\begin{array}{c}\text { Assumed population } \\
\text { density }\end{array}$ \\
\hline Urban traffic (UT) & Very high & Very high \\
\hline City background (CB) & High & High \\
\hline Suburban background (SB) & Medium & Medium \\
\hline Town background (TB) & Low & Low \\
\hline Rural background (RB) & Very low & Very low \\
\hline
\end{tabular}

To evaluate the occurrence / intensity of daily variability in the concentration of pollutants, the Maximum to Minimum Concentrations Ratio $(M M R)$ was determined. $M M R$ was calculated for the analyzed measurement stations as the maximum average hourly concentration of a given pollutant on a "typical" day divided by the minimum concentration value on a "typical" day. The "typical" day included averaged hourly values of concentrations from the analyzed periods of winter (from October to March), and summer (from May to August). Thus, the $M M R$ determined the level of changes between extreme values throughout a day. Additionally, for the selected database, the coefficient of variation of concentrations during the day was determined. It was calculated as the standard deviation of hourly concentrations of pollutants, divided by the arithmetic mean of concentrations. Therefore, coefficient of variation determined the level of hourly changes in pollutant concentrations relative to the daily average.

\section{Results and discussions}

Daily variability in concentrations of analyzed pollutants was expressed by means of the $M M R$ coefficient. The highest daily variability in winter periods occurred in the areas characterized by the highest population density (Table 3), i.e. in cities in urban traffic areas (UT). And the lowest occurred in areas with the lowest population density, i.e. in rural areas (RB). This could lead to conclusion that daily variability of air pollution in winter depend on the population density in the analyzed area. However, the highest $M M R$ values were observed for $\mathrm{NO}_{2}$ and $\mathrm{NO}_{\mathrm{x}}$, and the smallest for $\mathrm{PM}_{2.5}$. Level of nitrogen oxides increased and decreased significantly $(M M R>2.0)$ during a day. However, in the case of dusts, the ratio between average extreme daily values was only $1.28-1.71$. This indicated the occurrence of periods with significantly elevated and reduced levels of nitrogen oxides, while the level of dust remained similar throughout a day. In summer periods the daily variability of air pollution seemed to be independent from the population density of the analyzed areas (Table 4). For example, changes in the concentration of nitrogen oxides and ozone were the highest in towns, while the changes in $\mathrm{CO}$ and $\mathrm{PM}_{10}$ concentrations were the highest in cities. However, the lowest $M M R$ values occurred, depending on the pollutant type, in urban areas $\left(\mathrm{PM}_{2.5}\right.$ and benzene in UT, and $\mathrm{NO}_{2}$ and $\mathrm{O}_{3}$ in $\left.\mathrm{CB}\right)$, towns $\left(\mathrm{SO}_{2}\right.$ in $\left.\mathrm{TB}\right)$ and rural areas $\left(\mathrm{NO}_{x}, \mathrm{CO}\right.$ and $\mathrm{PM}_{10}$ in $\left.\mathrm{RB}\right)$. Interestingly, daily changes in nitrogen dioxide concentration were greater in suburban areas (SB) than in city centers (UT and CB). The highest daily variability of air pollution in summer, i.e. the highest $M M R$ values, occurred in all areas for $\mathrm{NO}_{2}, \mathrm{NO}_{\mathrm{x}}$ and $\mathrm{O}_{3}$, as well as for benzene in $\mathrm{SB}$ areas. However, the smallest daily variability of air pollution was for dusts $\left(\mathrm{PM}_{10}\right.$ and $\left.\mathrm{PM}_{2.5}\right)$, for which the $M M R$ ratio 
was 1.31-1.70. This meant that the level of dust remained similar throughout a day in summer, like in winter.

Table 3. Average hourly Maximum to Minimum Concentration Ratio $(M M R)$ for the analyzed areas in winter (dark grey $=$ the highest values, light grey $=$ the lowest values).

\begin{tabular}{|c|c|c|c|c|c|}
\hline \multirow{2}{*}{ Air pollutant } & \multicolumn{5}{|c|}{ MMR in winter period } \\
\cline { 2 - 6 } & UT & CB & SB & TB & RB \\
\hline $\mathrm{NO}_{2}$ & 2.59 & 2.23 & 1.87 & 1.90 & 1.46 \\
\hline $\mathrm{NO}_{\mathbf{x}}$ & 3.82 & 2.98 & 1.96 & 2.11 & 1.42 \\
\hline $\mathrm{O}_{3}$ & $\mathrm{n} / \mathrm{a}$ & 1.81 & 1.85 & 1.76 & 1.60 \\
\hline $\mathrm{SO}_{2}$ & 1.58 & 1.52 & 1.24 & 1.57 & 1.36 \\
\hline $\mathrm{CO}$ & 1.86 & 1.70 & 1.48 & 1.67 & 1.32 \\
\hline $\mathrm{PM}_{10}$ & 1.71 & 1.61 & 1.40 & 1.63 & 1.29 \\
\hline $\mathrm{PM}_{2.5}$ & 1.28 & 1.59 & 1.41 & 1.63 & $\mathrm{n} / \mathrm{a}$ \\
\hline $\mathrm{C}_{6} \mathrm{H}_{6}$ & 1.71 & 1.97 & 1.86 & $\mathrm{n} / \mathrm{a}$ & $\mathrm{n} / \mathrm{a}$ \\
\hline
\end{tabular}

Table 4. Average hourly Maximum to Minimum Concentration Ratio $(M M R)$ for the analyzed areas in summer (dark grey $=$ the highest values, light grey $=$ the lowest values).

\begin{tabular}{|c|c|c|c|c|c|}
\hline \multirow{2}{*}{ Air pollutant } & \multicolumn{5}{|c|}{ MMR in summer period } \\
\cline { 2 - 6 } & UT & CB & SB & TB & RB \\
\hline $\mathrm{NO}_{2}$ & 2.59 & 2.85 & 3.29 & 3.62 & 3.11 \\
\hline $\mathrm{NO}_{\mathbf{x}}$ & 3.13 & 3.14 & 2.93 & 3.24 & 2.76 \\
\hline $\mathrm{O}_{3}$ & $\mathrm{n} / \mathrm{a}$ & 2.60 & 2.64 & 3.15 & 2.97 \\
\hline $\mathrm{SO}_{2}$ & 1.83 & 1.85 & 1.85 & 1.63 & 1.72 \\
\hline $\mathrm{CO}$ & 2.18 & 1.67 & 1.65 & 1.51 & 1.17 \\
\hline $\mathrm{PM}_{10}$ & 1.57 & 1.47 & 1.52 & 1.49 & 1.43 \\
\hline $\mathrm{PM}_{2.5}$ & 1.31 & 1.68 & 1.63 & 1.70 & $\mathrm{n} / \mathrm{a}$ \\
\hline $\mathrm{C}_{6} \mathrm{H}_{6}$ & 1.97 & 2.34 & 3.87 & $\mathrm{n} / \mathrm{a}$ & $\mathrm{n} / \mathrm{a}$ \\
\hline
\end{tabular}

In addition, the $M M R$ calculated for selected locations were compared with data derived from the literature (Fig. 1), and a wide variety of results was visible. The most striking is the difference between the model, which used temporal profiles of emission factors of selected economy sectors [25], and the results from experimental measurements in European cities [26-28]. This could be due to the large size of the calculation grid in the model, while experimental measurements were made at specific points. The results of experimental measurements and numerical calculations differ especially in the case of $\mathrm{NO}_{2}$ concentrations. However the biggest daily fluctuations occurred for $\mathrm{O}_{3}$ concentrations. Research by Zheng et al. in Pearl River Delta in China showed that daily changes in $\mathrm{O}_{3}$ concentrations were significantly higher in urban areas $(\mathrm{CB})$ than in suburban (SB) and rural areas (RB) [29]. However, from the analysis performed in Poland, it was clear that $\mathrm{O}_{3}$ differed only slightly between all locations (UT, CB, SB, TB, RB). Also, a coefficient of variation [31] of air pollutant concentrations was determined for the analyzed locations. The coefficient was calculated as the standard deviation of hourly concentrations of pollutants, divided by the arithmetic mean of concentrations. In this case, the greatest variation in pollution levels occurred mostly in the summer (Table 5). Coefficient of variations for $\mathrm{NO}_{2}$ and benzene generally decreased with increasing assumed density of emissions. But increased for $\mathrm{CO}$ and $\mathrm{PM}_{10}$. However, in the case of other pollutants, no clear dependencies were observed. Therefore it could be concluded that the deviation of $\mathrm{NO}_{\mathrm{x}}, \mathrm{O}_{3}, \mathrm{SO}_{2}$ and $\mathrm{PM}_{2.5}$ levels from the daily average does not depend on the assumed density of emissions. 


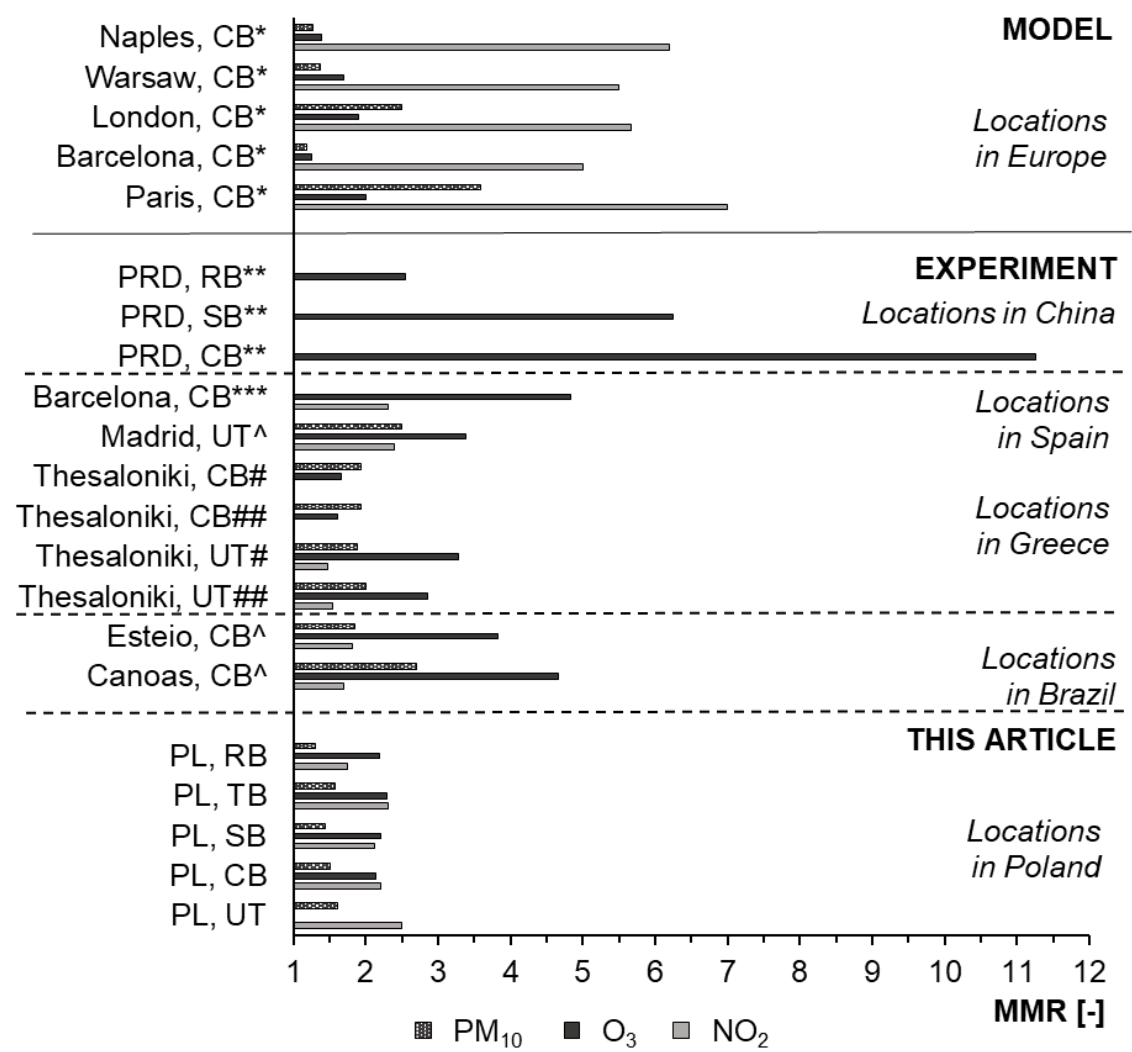

Fig. 1. Average dialy variability of air pollutants. Own study based on : *Menut et al. [25], **Zheng et al. [29], ***Perez et al., summer period [26], \#Vouitsis et al., summer period [27], \#\#Vouitsis et al., winter period [27], ^Moreno et al., winter period [28], ${ }^{\wedge}$ Agudelo-Castaneda and Teixeira [30].

Table 5. Coefficient of variation (\%) of average hourly concentrations in a day, calculated as the standard deviation divided by the arithmetic mean of concentrations (dark grey $=$ the highest values, light grey $=$ the lowest values).

\begin{tabular}{|c|c|c|c|c|c|c|c|c|c|c|}
\hline \multirow{2}{*}{ Air pollutant } & \multicolumn{4}{|c|}{$\begin{array}{c}\text { Coefficient of variation (\%) } \\
\text { Winter periods }\end{array}$} & \multicolumn{4}{c|}{ Coefficient of variation (\%) } \\
\cline { 2 - 14 } & $\mathrm{UT}$ & $\mathrm{CB}$ & $\mathrm{SB}$ & $\mathrm{TB}$ & $\mathrm{RB}$ & $\mathrm{UT}$ & $\mathrm{CB}$ & $\mathrm{SB}$ & $\mathrm{TB}$ & $\mathrm{RB}$ \\
\hline $\mathrm{NO}_{2}$ & 37 & 38 & 37 & 39 & 39 & 41 & 53 & 55 & 60 & 62 \\
\hline $\mathrm{NO}_{\mathbf{x}}$ & 51 & 52 & 45 & 50 & 39 & 50 & 61 & 57 & 61 & 58 \\
\hline $\mathrm{O}_{3}$ & $\mathrm{n} / \mathrm{a}$ & 43 & 44 & 43 & 35 & $\mathrm{n} / \mathrm{a}$ & 39 & 40 & 44 & 43 \\
\hline $\mathrm{SO}_{2}$ & $\mathrm{n} / \mathrm{a}$ & 37 & 39 & 39 & 40 & $\mathrm{n} / \mathrm{a}$ & 51 & 48 & 42 & 43 \\
\hline $\mathrm{CO}$ & 32 & 32 & 27 & 32 & 26 & 33 & 29 & 28 & 28 & 19 \\
\hline $\mathrm{PM}_{10}$ & 39 & 36 & 35 & 34 & 36 & 37 & 36 & 35 & 36 & 33 \\
\hline $\mathrm{PM}_{2.5}$ & 32 & 36 & 33 & 35 & $\mathrm{n} / \mathrm{a}$ & 29 & 37 & 34 & 30 & $\mathrm{n} / \mathrm{a}$ \\
\hline benzene & 36 & 44 & 57 & $\mathrm{n} / \mathrm{a}$ & $\mathrm{n} / \mathrm{a}$ & 45 & 62 & 106 & $\mathrm{n} / \mathrm{a}$ & $\mathrm{n} / \mathrm{a}$ \\
\hline
\end{tabular}




\section{Conclusions}

In the winter, the character of changes of air pollution depended on the analyzed area. Level of this changes $(M M R)$ increased along with assumed emission density. The exceptions were concentrations of finer dust particles $\left(\mathrm{PM}_{2.5}\right)$, which showed the opposite pattern. However, in summer there was no clear dependency between daily variability of concentrations and the assumed emission density. In winter, when the pollution level was usually high, the daily variability was greater in more congested areas. But in summer, when air pollution was usually lower, there was no such dependency. However, greater variability of pollutant concentrations occurred in summer than in winter. This could be related to the lower "background" level of air pollution in the summer. Also, the highest daily variability concerned nitrogen oxides, and the smallest concerned dusts. This indicated the occurrence of significant differences in air quality in the "most" and "least favorable" periods during a day. Which is important in terms of protecting the health of people living in the areas of cities, towns and villages. Also, the analysis of literature [21-26] showed similar, or larger, daily variability of air pollution in urban areas in other countries around the world. However, when considering the coefficient of variation, the daily changes in air quality were not unequivocally dependent on the density of the analyzed cities. In addition, this was comparable in winter and in summer. However, variability in concentrations of carbon monoxide and particulate matter $\left(\mathrm{PM}_{10}\right)$ were decreasing along with the decrease in density of emissions (and also population). The coefficient of variation was the highest for nitrogen oxides and for benzene, which indicated large deviations of these values from the daily average, and the lowest coefficient was for $\mathrm{CO}, \mathrm{PM}_{10}$ and $\mathrm{PM}_{2.5}$. Nevertheless, in the winter generally there was the highest daily variability of air pollution in the most congested areas (cities), and the lowest in the least populated places (villages). However, in the summer, the daily variability was different in all locations. Knowledge about the daily changes in concentrations of air pollutants in areas of various characteristics, may help in better planning of air protection strategies in modern cities, and thus may positively affect the protection of health of people living in those areas.

\section{References}

1. M. Baciak, K. Warmiński, A. Bęś, Forest Research Papers 76, 401-409 (2015)

2. R. Afroz, M. N. Hassan, N. A. Ibrahim, Environmental Research 92, 71-77 (2003)

3. B. Brunekreef, S. T. Holtage, Lancet 360, 1233-1242 (2002)

4. World Health Organisation, Air Quality Quidelines for Europe (WHO Regional Publications, Copenhagen, 2000)

5. World Health Organisation, Air Quality Quidelines for Europe - Global Update 2005. (WHO Regional Publications, Copenhagen, 2005)

6. R. Bascom, P. A. Bromberg, D. A. Costa, R. Devlin, D. W. Dockery, M. W. Frampton, W. Lambert, J. M. Samet, F. E. Speizer, M. Utell, American Journal of Respiratory and Critical Care Medicine 153, 3-50 (1996)

7. C. Reboul, J. Boissière, L. André, G. Meyer, P. Bideaux, G. Fouret, C. Feillet-Coudray, P. Obert, A. Lacampagne, J. Thireau, O. Cazorla, S. Richard, Scientific Reports 7, 39715 (2017)

8. H. Lawin, L. Ayi Fanou, V. Hinson, J. Wanjiku, N. K. Ukwaja, S. B. Gordon, B. Fayomi, J. R. Balmes, P. Houngbegnon, E. Avokpaho, A. Sanni, BMC Public Health 17, 320 (2017) 
9. D. F. Costa, M. Goldbaum, Ciencia \& Saude Coletiva 22, 2681-2692 (2017)

10. C. B. B. Guerreiro, V. Foltescu, F. de Leeuw, Atmos. Environ. 98, 376-384 (2014)

11. Directive 2008/50/EC of the European Parliament and of the Council of 21 May 2008, On Ambient Air Quality and Cleaner Air for Europe, OJ L 152, 11.6.2008, 1-44.

12. R. Cichowicz, E3S Web Conf. 28, 01007 (2018)

13. R. Cichowicz, A. Stelęgowski, Chemical Papers (2018)

14. R. Cichowicz, G. Wielgosiński, A. Targaszewska, Ecological Chemistry and Engineering S 23, 49-60 (2016)

15. R. Cichowicz, G. Wielgosiński, W. Fetter, Environ. Monit. Assess. 12, 189-605 (2017)

16. G. Wielgosiński, J. Czerwińska, O. Namiecińska, R. Cichowicz, E3S Web Conf. 28, 01039 (2018)

17. https://www.eea.europa.eu/publications/2599XXX/page010.html

18. K. N. Priftis, M. B. Anthracopoulos, A. G. Paliatsos, G. Tzavelas, A. Nikolaou-Papanagiotou, P. Douridas, P. Nicolaidou, Mantzouranis E, Respiratory Medicine 101, 98-106 (2007)

19. L. Dijkstra, H. Poelman, Cities in Europe - The new OECD-EU definition (European Comission, Brussels, 2012)

20. L. Servillo, R. Atkinson, I. Smith, A. Russo, L. Sykora, C. Demaziere, A. Hamdouch, TOWN, small and medium sized towns in their functional territorial context - Final Report (Espon, Luxembourg, 2014)

21. J. Putaud, F. Raes, R. van Dingenen, E. Brüggemann, M. Facchini, S. Decesari, A. Wiedensohler, Atmos. Environ. 38, 2579-95 (2004)

22. A. Hagenbjörk, E. Malmqvist, K. Mattisson, N.J. Sommar, L. Modig, Environ Monit. Assess. 189, 161 (2017)

23. I. Vouitsis, S. Amanatidis, L. Ntziachristos, A. Kelessis, M. Petrakakis, I. Stamos, Z. Samaras, Atmos. Environ. 122, 577-587 (2015)

24. B. Dębski, A. Olecka, K. Bebkiewicz, I. Kargulewicz, J. Rutkowski, D. Zasina, M. Zimakowska-Laskowska, M. Żaczek, National balance of $\mathrm{SO}_{2}, \mathrm{NO}_{x}, \mathrm{CO}, \mathrm{NH}_{3}$, NMLZO, dust, heavy metals and TZO in the SNAP and NFR classification system. Basic report (Warsaw, The National Centre for Emissions Management, 2015)

25. L. Menut, A. Goussebaile, B. Bessagnet, D. Khvorostiyanov, A. Ung, Atmos. Environ. 49, 233-244 (2012)

26. N. Pérez, J. Pey, M. Cusack, C. Reche, X. Querol, A. Alastuey, M. Viana, Aerosol Science and Technology 44, 487-499 (2010)

27. I. Vouitsis, S. Amanatidis, L. Ntziachristos, A. Kelessis, M. Petrakakis, I. Stamos, E. Mitsakis, Z. Samaras, Atmos. Environ. 122, 577-587 (2015)

28. T. Moreno, A. Karanasiou, F. Amato, F. Lucarelli, S. Nava, G. Calzolai, M. Chiari, E. Coz, B. Artinano, J. Lumbreras, R. Borge, C. Linares, A. Alastuey, X. Querol, W. Gibbons, Atmos. Environ. 68, 33-44 (2013)

29. J. Zheng, L. Zhong, T. Wang, P. K. K. Louie, Z. Li, Atmos. Environ. 44, 814-823 (2010)

30. D. M. Agudelo-Castaneda, E. C. Teixeira, F. N. Pereira, Atmos. Pollut. Res. 5, 411-420 (2014)

31. C. E. Brown, Coefficient of Variation, In: Applied Multivariate Statistics in Geohydrology and Related Sciences (Springer, Berlin-Heidelberg, 1998) 